\title{
Potencial de caracteres na avaliação da arquitetura de plantas de feijão
}

\author{
Monique Maculan Moura(1), Pedro Crescêncio Souza Carneiro(1), José Eustáquio de Souza Carneiro(1) \\ e Cosme Damião Cruz ${ }^{(1)}$
}

(1)Universidade Federal de Viçosa, CEP 36570-000 Viçosa, MG. E-mail: mnikkii@hotmail.com, carneiro@ufv.br, jesc@ufv.br, cdcruz@ufv.br

Resumo - O objetivo deste trabalho foi identificar indicadores efetivos da arquitetura de plantas em feijoeiro, para subsidiar, ou substituir, a avaliação por notas. Trinta e seis linhagens de feijão foram avaliadas quanto aos principais caracteres relacionados à arquitetura de plantas e a caracteres agronômicos, em duas safras. Os experimentos foram realizados em blocos ao acaso, com três repetições, em Coimbra, MG. A análise de trilha indicou que o ângulo de inserção dos ramos, a altura das plantas na colheita e o diâmetro do hipocótilo foram os principais caracteres determinantes da arquitetura de plantas do feijoeiro. O diâmetro do hipocótilo esteve fortemente associado com a nota de arquitetura e possibilitou elevada acurácia e precisão de mensuração. Essa característica é facilmente mensurada e é indicador efetivo da arquitetura de plantas do feijoeiro.

Termos para indexação: altura de inserção, colheita mecanizada, diâmetro do hipocótilo, hábito de crescimento, plantas eretas, seleção simultânea.

\section{Potential of characters for evaluating common bean plant architecture}

\begin{abstract}
The objective of this work was to identify effective indicators of plant architecture in common bean, to subsidize or replace the evaluation by scores. Thirty-six common bean lines were evaluated regarding the main characters related to plant architecture and agronomic traits, in two harvest seasons. The experiments were carried out in a randomized complete block design with three replicates in Coimbra, MG, Brazil. Path analysis showed that the insertion angle of branches, plant height at harvest, and hypocotyl diameter were the main determinants of plant architecture of common bean. Hypocotyl diameter was strongly related to the architecture score, and allowed high accuracy and precision in measurement. This trait is easily measured and is an effective indicator of bean plant architecture.

Index terms: insertion height, mechanical harvest, hypocotyl diameter, growth habit, erect plants, simultaneous selection.
\end{abstract}

\section{Introdução}

A colheita do feijoeiro (Phaseolus vulgaris L.) tem alto custo da mão de obra, demandada para o arranquio e o enleiramento das plantas. Esse fato comumente limita a extensão das áreas de cultivo. As cultivares atualmente utilizadas em áreas irrigadas apresentam, principalmente, tipo de grão carioca e hábito de crescimento prostrado. Contudo, a tendência é de que novas cultivares apresentem porte o mais ereto possível e maior tolerância ao acamamento (Ramalho et al., 1998; Cunha et al., 2005; Menezes Júnior et al., 2008; Mendes et al., 2009). Espera-se, com isso, obter uma planta fisiologicamente mais eficiente e, sobretudo, que facilite os tratos culturais e possibilite a colheita mecanizada. Além disso, essas características podem minimizar a incidência de doenças, especialmente o mofo-branco, aumentar a qualidade tecnológica do grão e diminuir as perdas na colheita (Collicchio et al., 1997).

Teixeira et al. (1999) obtiveram informações acerca de caracteres relacionados ao porte das plantas de feijão e constataram que o comprimento dos entrenós foi o caráter com maior variação, controlado predominantemente por herança de efeito aditivo. Santos \& Vencovsky (1986a) também observaram que a ação gênica aditiva foi predominante em relação à dominância dos caracteres altura de inserção da primeira vagem, comprimento da haste principal e número e comprimento médio de entrenós na haste principal.

Estudos, como os realizados por Menezes Júnior et al. (2008), Mendes et al. (2009) e Silva et al. (2009), evidenciam a possibilidade de se obter, simultaneamente, plantas de arquitetura ereta e de elevada produtividade de grãos. O uso de escala de 
notas é o critério mais utilizado pelos programas de melhoramento para avaliar a arquitetura da planta do feijoeiro (Teixeira et al., 1999; Menezes Júnior et al., 2008; Mendes et al., 2009; Silva et al., 2009). Esse critério, no entanto, baseia-se na avaliação visual, é trabalhoso e demanda experiência para uma avaliação precisa. De modo geral, a atribuição de notas é realizada por pelo menos três avaliadores, com uso da média das notas auferidas em cada parcela (Collicchio et al., 1997). As notas são atribuídas de acordo com caracteres determinantes do porte das plantas, como número e ângulo de inserção dos ramos, presença e comprimento de guias, altura de inserção da primeira vagem, tamanho e distribuição das vagens na planta, altura da planta e acamamento (Ramalho et al., 1998). Outra forma de atribuição de notas é a busca pelo consenso entre três avaliadores, ao se considerar os caracteres citados.

O objetivo deste trabalho foi identificar indicadores efetivos da arquitetura de plantas em feijoeiro, para subsidiar, ou substituir, a avaliação por notas.

\section{Material e Métodos}

Trinta e seis linhagens de feijoeiro (Tabela 1), do Banco Ativo de Germoplasma de Feijão da Universidade Federal de Viçosa (UFV), foram avaliadas quanto a caracteres relacionados à arquitetura de plantas e à produtividade de grãos, nas safras de inverno de 2007 e 2009. O experimento foi conduzido no campo experimental de Coimbra, MG, pertencente ao Departamento de Fitotecnia da UFV.

Utilizou-se o delineamento de blocos ao acaso, com três repetições. As parcelas foram constituídas por três linhas de $3 \mathrm{~m}$, espaçadas de $0,5 \mathrm{~m}$, em 2007, e por quatro linhas, em 2009.

As características avaliadas foram: dias até o florescimento, dias até a colheita, nota de arquitetura de plantas no florescimento e na colheita, altura média de plantas da parcela no florescimento e na colheita, produtividade de grãos, altura de inserção da primeira vagem medida no campo e no laboratório (após a colheita), ângulo de inserção dos ramos, número de vagens na haste principal e nos ramos, diâmetro do epicótilo e do hipocótilo, número de ramos totais e abortados, número de entrenós na haste principal e nos ramos com vagem, comprimento dos quatro primeiros entrenós na haste principal (CE1, CE2, CE3 e CE4), comprimento total de entrenós, número de grãos por vagem e massa de 100 grãos.

$\mathrm{Na}$ avaliação das notas de arquitetura, no florescimento e na colheita, foram consideradas as linhas centrais da parcela, tendo-se utilizado escala de notas de 1 a 9, em que 1 indica as plantas totalmente eretas e 9, as prostradas (Collicchio et al., 1997).

A altura de plantas foi medida do nível do solo até o ápice da haste principal, tendo-se considerado três pontos representativos na parcela.

No experimento de 2007, foram colhidas as duas fileiras laterais para obtenção da produtividade de grãos.

Tabela 1. Nome de registro, tipo de grão e procedência das 36 linhagens utilizadas.

\begin{tabular}{|c|c|c|}
\hline Genótipo & $\begin{array}{c}\text { Grupo } \\
\text { comercial }\end{array}$ & Procedência \\
\hline IPA 6 & Mulatinho & IPA \\
\hline BRS Horizonte & Carioca & Embrapa \\
\hline BRSMG Madrepérola & Carioca & Convênio UFV/Ufla/Embrapa/Epamig \\
\hline VC 6 & Carioca & Convênio UFV/Ufla/Embrapa/Epamig \\
\hline Carioca 1030 & Carioca & IAC \\
\hline BRS Pérola & Carioca & Embrapa \\
\hline BRSMG Talismã & Carioca & Convênio UFV/Ufla/Embrapa/Epamig \\
\hline BRSMG Majestoso & Carioca & Convênio UFV/Ufla/Embrapa/Epamig \\
\hline Ouro Negro & Preto & UFV/Epamig \\
\hline Meia Noite & Preto & Epamig \\
\hline BRS Supremo & Preto & Embrapa \\
\hline BRS Valente & Preto & Embrapa \\
\hline Ouro Vermelho & Vermelho & Convênio UFV/Ufla/Embrapa/Epamig \\
\hline Vermelhinho & Vermelho & Produtor, Viçosa, MG \\
\hline PF 902975 & Carioca & Esal/Embrapa \\
\hline CNFC8006 & Carioca & Embrapa \\
\hline CNFC9466 & Carioca & Embrapa \\
\hline CNFC9455 & Carioca & Embrapa \\
\hline CNFC9454 & Carioca & Embrapa \\
\hline CNFC9458 & Carioca & Embrapa \\
\hline A 805 & Carioca & Ciat \\
\hline UTF 0019 & Carioca & Cefet, Pato Branco \\
\hline LP 98-76 & Carioca & Iapar \\
\hline LM 93204351 & Carioca & Embrapa \\
\hline $18404 \mathrm{HA}$ & Preto & Estação Experimental Patos \\
\hline Cornell 49-242 & Preto & Austrália \\
\hline LM 21135 & Preto & Embrapa \\
\hline Fe 732015 & Preto & Embrapa \\
\hline HA 911104 & Preto & Embrapa \\
\hline ICA Pijão & Preto & Ciat, Colômbia \\
\hline Iapar 44 & Preto & Iapar \\
\hline Porrillo 70 & Preto & Ciat, Colômbia \\
\hline ТВ 94-01 & Preto & Embrapa \\
\hline Rico 1735 & Preto & UFV/Epamig \\
\hline A 170 & Mulatinho & Ciat, Colômbia \\
\hline A 525 & Mulatinho & Ciat, Colômbia \\
\hline
\end{tabular}


$\mathrm{Na}$ safra de 2009, uma das fileiras centrais foi utilizada para essa avaliação, enquanto a outra foi usada para mensurar as características avaliadas após a colheita. Para medição da altura de inserção da primeira vagem no campo, tomou-se como referência o nível do solo até o ponto de inserção da primeira vagem no racimo, sem erguer a planta. Já a medida da altura de inserção da primeira vagem no laboratório, após a colheita, foi feita com a planta mantida de forma ereta. O ângulo de inserção dos ramos foi medido com auxílio de régua semicircular entre $0^{\circ}$ e $180^{\circ}$ (transferidor), tendo-se considerado os três ramos seguintes aos ramos das folhas primárias.

As médias do número de vagens e de ramos foram obtidas de nove plantas representativas da parcela. As medidas do diâmetro do epicótilo e do hipocótilo foram tomadas a $1 \mathrm{~cm}$ do nó cotiledonar, com uso de paquímetro digital. Para contagem do número de entrenós, foram considerados apenas os pertencentes a ramos ou racimos com vagens. As medidas do comprimento dos quatro primeiros entrenós na haste principal, em centímetros, foram feitas a partir do nó cotiledonar.

Os dados foram submetidos à análise de variância individual, para cada safra, e conjunta, para as duas safras, de acordo com Ramalho et al. (2005). Em todas as análises, os efeitos foram considerados como fixos, exceto o erro.

Foram obtidas as estimativas dos coeficientes de correlação fenotípica, genotípica e ambiental, entre os pares de caracteres, conforme descrito por Cruz et al. (2004).Afim de testar a significância desses coeficientes, foi utilizado o teste $t$, para as correlações fenotípicas, e o procedimento de "bootstrap" com 5.000 simulações, para as genotípicas e as ambientais. Os coeficientes de correlação genotípica foram desdobrados em componentes de efeito direto e indireto, por meio da análise de trilha descrita por Cruz et al. (2004). Para essa análise, os dados relativos aos caracteres foram padronizados. Na safra de 2007, a nota de arquitetura na colheita foi considerada como variável principal ou básica, e os caracteres produtividade, ângulo de inserção de ramos, número de vagens na haste principal e nos ramos, número de grãos por vagem, diâmetro do hipocótilo, número de ramos totais e comprimento do primeiro entrenó foram considerados variáveis explicativas primárias. Já os caracteres dias até o florescimento, altura de inserção no campo, arquitetura na colheita e número de entrenós nos ramos com vagem foram considerados variáveis explicativas secundárias. $\mathrm{Na}$ definição desse diagrama de trilha (diagrama 1), cuidou-se para que o conjunto de variáveis explicativas primárias e secundárias não apresentasse colinearidade em níveis prejudiciais às estimativas dos coeficientes de regressão. O diagnóstico de multicolinearidade foi realizado conforme Cruz \& Carneiro (2006). Esse diagrama de trilha não incluiu as informações relativas ao desdobramento dos coeficientes de correlação genotípica das variáveis dias até a colheita e número de entrenós na haste principal com a variável básica nota de arquitetura na colheita. Assim, um segundo diagrama de trilha (diagrama 2) foi estabelecido, tendo-se considerado o mesmo conjunto de variáveis explicativas primárias e essas duas variáveis como variáveis explicativas secundárias.

Na safra de 2009, seguindo o critério de definição dos diagramas de trilha adotados na safra de 2007, obteve-se o mesmo conjunto de variáveis explicativas primárias, com exceção da variável número de grãos por vagem, que foi substituída pela massa de 100 grãos. Para o conjunto de variáveis explicativas secundárias, foram considerados a arquitetura na colheita, $o$ número de grãos por vagem, o número de entrenós na haste principal e nos ramos com vagem. Com este diagrama de trilha (diagrama 3), ficaram faltando apenas as informações relativas ao desdobramento dos coeficientes de correlação genotípica das variáveis dias até o florescimento e altura de inserção no campo com a variável básica arquitetura na colheita. Assim, para a safra de 2009, também foi estabelecido um segundo diagrama de trilha (diagrama 4), que considerou o mesmo conjunto de variáveis explicativas primárias e essas duas variáveis como variáveis explicativas secundárias. Todas as análises foram realizadas com 0 auxílio do programa Genes (Cruz, 2006).

\section{Resultados e Discussão}

Nas análises de variância individuais, observou-se efeito significativo dos genótipos sobre os caracteres mensurados, o que indica variabilidade genética entre as linhagens avaliadas. $\mathrm{Na}$ análise de variância conjunta (Tabela 2), o efeito dos genótipos também foi significativo para todos os caracteres avaliados. Quanto aos ambientes (anos de avaliação), o efeito foi significativo para a maior parte dos caracteres, com 
exceção de nota de arquitetura na colheita, altura no florescimento, altura de inserção avaliada no laboratório e comprimentos do segundo, do terceiro e do quarto entrenós. $\mathrm{O}$ ambiente normalmente tem expressiva influência sobre a arquitetura das plantas (Teixeira et al., 1999; Bassett, 2004; Moreto et al., 2007).

A interação genótipo $\mathrm{x}$ ambiente apresentou efeito significativo para todas as características avaliadas, à exceção de nota de arquitetura na colheita e número de grãos por vagem (Tabela 2). A ocorrência de interação genótipo $\mathrm{x}$ ambiente para produtividade de grãos e arquitetura de plantas na cultura do feijoeiro tem sido frequentemente relatada na literatura (Collicchio et al., 1997; Oliveira et al., 2006; Moreto et al., 2007; Pereira et al., 2009).

O coeficiente de variação experimental não superou $20 \%$ para a maioria dos caracteres, o que indica boa precisão (Tabela 2). As estimativas do coeficiente de determinação genotípico, com base nas médias das safras, foram de alta magnitude para todas as características, com valores entre 66 e $98 \%$, o que é indicativo de confiabilidade do valor fenotípico médio como preditor do valor genotípico. Embora seja uma avaliação visual, a avaliação da arquitetura de plantas por notas apresentou elevada acurácia $\left(h^{2}=96,86 \%\right)$.

Em geral, as estimativas dos coeficientes de correlação fenotípica e genotípica apresentaram o mesmo sinal (Tabela 3). Os sinais divergentes observados para alguns pares de caracteres indicam a existência de mecanismos fisiológicos distintos que atuam na determinação dos caracteres envolvidos (Falconer \& Mackay, 1996). As correlações genotípicas foram, em geral, superiores às ambientais e às fenotípicas, o que mostra maior contribuição dos fatores genéticos do que os ambientais na expressão desses caracteres. Santos \& Vencovsky (1986a) observaram que a ação gênica aditiva é predominante em relação à de dominância, para os caracteres altura de inserção da primeira vagem, comprimento da haste principal e número e comprimento médio dos entrenós na haste principal. Teixeira et al. (1999) também constataram que o comprimento dos entrenós é determinado predominantemente por efeito aditivo. Em um dialelo parcial, com 14 das 36 linhagens avaliadas no presente trabalho, Silva (2011) também concluiu que a ação gênica aditiva é predominante em

Tabela 2. Resumo das análises de variância conjuntas de 23 caracteres avaliados no inverno de 2007 e de 2009.

\begin{tabular}{|c|c|c|c|c|c|c|}
\hline \multirow[t]{2}{*}{ Caráter } & \multicolumn{3}{|c|}{ Quadrados médios } & \multirow{2}{*}{$\begin{array}{l}\text { CV } \\
(\%)\end{array}$} & \multirow[t]{2}{*}{$\mathrm{h}^{2(1)}$} & \multirow[t]{2}{*}{ Média } \\
\hline & Genótipos (G) & Ambientes (A) & GxA & & & \\
\hline Dias até florescimento & $11,85 * *$ & $59,12 *$ & $2,80 * *$ & 1,71 & 95,94 & 43,86 \\
\hline Nota de arquitetura no florescimento & $14,79 * *$ & $57,04 *$ & $1,17 * *$ & 14,37 & 97,36 & 4,35 \\
\hline Nota de arquitetura na colheita & $17,32 * *$ & $2,24^{\mathrm{ns}}$ & $0,71^{\mathrm{ns}}$ & 15,50 & 96,86 & 4,75 \\
\hline Produtividade $\left(\mathrm{kg} \mathrm{ha}^{-1}\right)$ & $600.428,94 * *$ & $8.105 .694,23^{*}$ & $319.570,91 * *$ & 13,81 & 76,39 & 2.726 \\
\hline Altura no florescimento $(\mathrm{cm})$ & $92,09 * *$ & $290,28^{\mathrm{ns}}$ & $107,53 * *$ & 7,58 & 88,95 & 42,10 \\
\hline Altura na colheita $(\mathrm{cm})$ & $333,08 * *$ & $6222,65 * *$ & $81,13 * *$ & 16,29 & 89,94 & 35,32 \\
\hline Inserção $1^{\mathrm{a}}$ vagem no campo $(\mathrm{cm})$ & $16,13 * *$ & $534,96 * *$ & $11,26 * *$ & 13,68 & 76,49 & 14,24 \\
\hline Ângulo de inserção de ramos & $145,49 * *$ & $3448,46 * *$ & $18,98 * *$ & 10,80 & 92,06 & 31,46 \\
\hline Vagens na haste principal & $14,47 * *$ & $12,58 * *$ & $3,91 * *$ & 17,27 & 90,73 & 6,71 \\
\hline Grãos por vagem & $1,02 * *$ & $19,75^{*}$ & $0,28^{\text {ns }}$ & 10,96 & 68,54 & 5,16 \\
\hline Vagens nos ramos & $16,89 * *$ & $155,86^{*}$ & $8,72 * *$ & 22,63 & 82,27 & 7,65 \\
\hline Diâmetro do hipocótilo (cm) & $0,02 * *$ & $0,41 * *$ & $0,00 * *$ & 6,68 & 93,47 & 0,54 \\
\hline Diâmetro do epicótilo (cm) & $0,02 * *$ & $1,01 * *$ & $0,01 * *$ & 8,56 & 88,47 & 0,53 \\
\hline Número total de ramos & $1,67 * *$ & $24,74 * *$ & $0,85^{* *}$ & 12,68 & 81,62 & 4,37 \\
\hline Número de ramos abortados & $0,78 * *$ & $17,02 * *$ & $0,56 * *$ & 27,13 & 66,84 & 1,87 \\
\hline Inserção $1^{a}$ vagem no laboratório $(\mathrm{cm})$ & $19,89 * *$ & $106,09^{\text {ns }}$ & $7,41 * *$ & 13,49 & 80,88 & 14,45 \\
\hline Entrenós na haste principal & $2,81 * *$ & $25,06 * *$ & $0,95 * *$ & 6,18 & 90,35 & 8,42 \\
\hline Entrenós nos ramos com vagem & $7,88 * *$ & $206,72 * *$ & $5,24 * *$ & 21,33 & 80,60 & 5,80 \\
\hline Comprimento 1e entrenó (cm) & $0,85 * *$ & $4,87 * *$ & $0,12 * *$ & 7,88 & 93,80 & 2,91 \\
\hline Comprimento 2o entrenó $(\mathrm{cm})$ & $0,61 * *$ & $0,06^{\mathrm{ns}}$ & $0,05 * *$ & 9,49 & 95,33 & 1,78 \\
\hline Comprimento 3o entrenó (cm) & $0,59 * *$ & $0,04^{\mathrm{ns}}$ & $0,21 * *$ & 17,65 & 84,97 & 1,69 \\
\hline Comprimento 4o entrenó (cm) & $0,76^{* *}$ & $0,03^{\text {ns }}$ & $0,28 * *$ & 17,36 & 79,18 & 2,28 \\
\hline Comprimento total de entrenós $(\mathrm{cm})$ & $74,07 * *$ & $2995,90 * *$ & $52,58 * *$ & 13,75 & 70,68 & 33,88 \\
\hline
\end{tabular}

${ }^{(1)} \mathrm{h}^{2}$, coeficiente de determinação genotípico. ns Não significativo. ** e *Significativo pelo teste $\mathrm{F}$, a 1 e $5 \%$ de probabilidade, respectivamente. 


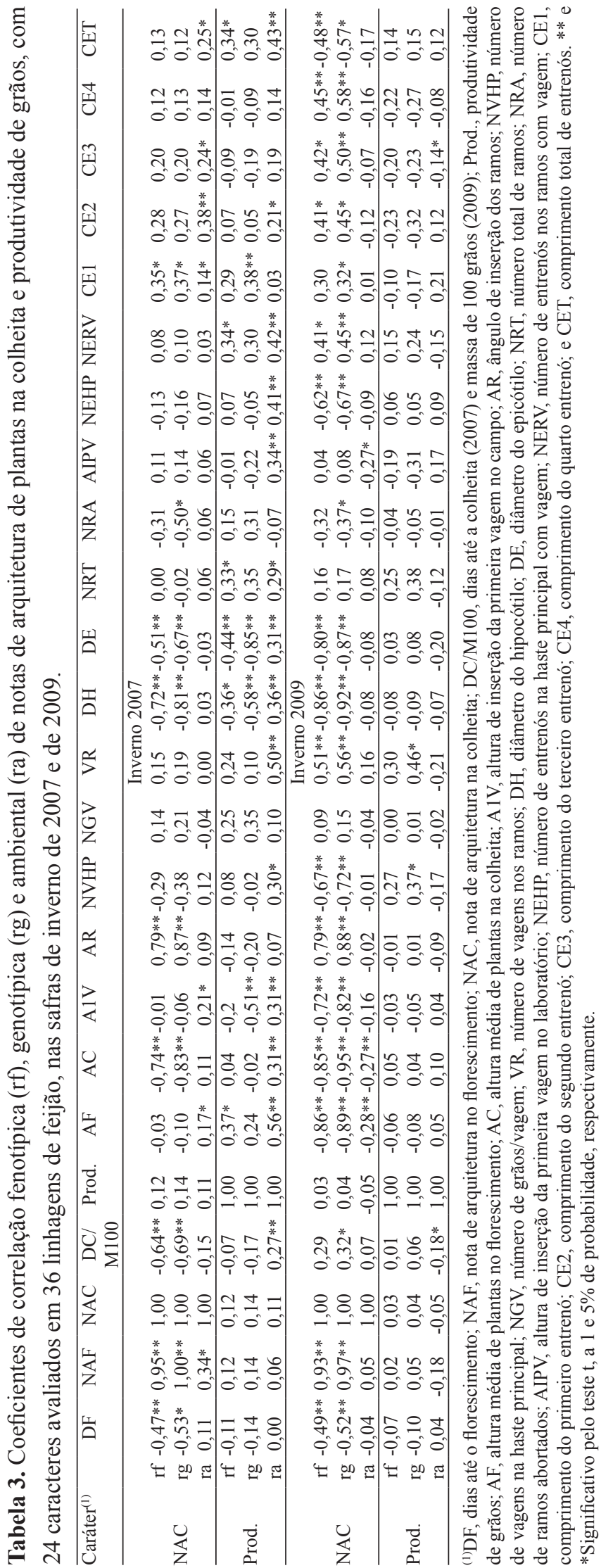

relação à de dominância, para os caracteres nota de arquitetura na colheita e diâmetro do hipocótilo.

Vale ressaltar que, nos anos de avaliação (2007 e 2009), as estimativas de correlação genotípica entre as avaliações da arquitetura no florescimento e na colheita tiveram valores próximos de 1 , indício de que essa avaliação pode ser realizada tanto no florescimento quanto próximo à colheita. A atribuição de notas de arquitetura próximo do período de colheita oferece menor dificuldade, em razão da senescência das folhas. Além disso, o efeito da interação genótipo $\mathrm{x}$ ambiente não foi significativo para a nota atribuída na colheita (Tabela 2).

A nota de arquitetura na colheita, característica alvo avaliada no presente trabalho, correlacionou-se genotípica e fenotipicamente $(>0,65)$ com os caracteres ângulo de inserção de ramos, altura na colheita e diâmetros do hipocótilo e do epicótilo (Tabela 3). O primeiro atributo que um caráter deve apresentar para ser utilizado na seleção indireta de plantas mais eretas é uma elevada correlação genotípica com a nota de arquitetura na colheita. Portanto, os caracteres mencionados apresentam potencial para esse fim, com destaque para ângulo dos ramos e diâmetro do hipocótilo que, além das maiores estimativas de correlação genotípica, apresentaram elevada precisão e acurácia nas suas avaliações (Tabela 2). Segundo Cruz et al. (2004), a seleção indireta é importante para os programas de melhoramento, principalmente se a seleção com base no caráter principal apresenta alguma dificuldade.

$\mathrm{Na}$ safra de 2007, embora não tenha havido associação linear da produtividade e dos componentes de rendimento com as notas de arquitetura de plantas, observou-se que a produtividade esteve negativamente associada com a altura de inserção da primeira vagem no campo e o diâmetro do hipocótilo e do epicótilo. $\mathrm{Na}$ safra de 2009, a produtividade não apresentou associação com o diâmetro do hipocótilo ou com qualquer outra característica relacionada à arquitetura de plantas. Esses resultados evidenciam a possibilidade de se obter, simultaneamente, plantas de arquitetura ereta e de elevada produtividade de grãos. Resultados similares foram obtidos por Menezes Júnior et al. (2008), Mendes et al. (2009) e Silva et al. (2009). Tanto em 2007 como em 2009, não houve correlação entre produtividade de grãos e componentes de produção. Segundo Santos \& Vencovsky (1986b), a correlação entre esses caracteres, 
relatada na literatura, varia amplamente, com valores positivos, nulos e até negativos.

De modo geral, as plantas eretas foram mais altas e mais tardias, e apresentaram maior diâmetro do hipocótilo e do epicótilo, maior número de entrenós na haste principal, entrenós mais curtos, primeira vagem mais alta, menor número de entrenós nos ramos, ramos com ângulos menores em relação ao eixo principal e menor número de vagens (Tabela 3 ).

As estimativas dos efeitos diretos e indiretos das variáveis primárias sobre a variável básica (nota de arquitetura na colheita) tiveram magnitudes semelhantes nos dois anos (Tabela 4). De acordo com essas estimativas, o caráter diâmetro do hipocótilo apresentou elevadas estimativas de correlação e de efeito direto sobre a nota de arquitetura na colheita, cujas estimativas foram de $-0,89$ e $-0,81$, para a safra de 2007 , e de $-0,75$ e $-0,92$, para a de 2009 , respectivamente.

O ângulo de inserção dos ramos teve alta correlação, mas efeito direto relativamente baixo sobre a nota de arquitetura na colheita, em ambas as safras (Tabela 4). Assim, progênies com maiores ângulos de inserção dos ramos apresentarão maior nota de arquitetura na colheita e, portanto, serão mais prostradas. Contudo, essa característica apresentou maior influência indireta, via diâmetro do hipocótilo, que apresenta correlação genética negativa com ângulo dos ramos. Dessa forma, a estratégia de se selecionar, entre as plantas de maior diâmetro do hipocótilo, aquelas com menor ângulo é indicada para se obter plantas mais eretas.

Em 2007, verificou-se que a produtividade de grãos apresentou baixa correlação com nota de arquitetura na colheita, além de efeito direto de sinal negativo considerável (Tabela 4). Cabe ressaltar que o maior efeito indireto para essa característica também foi observado via diâmetro do hipocótilo. Portanto, na obtenção de plantas de interesse agronômico, produtivas e com boa arquitetura, é necessário selecionar, entre as mais produtivas, as de maior diâmetro do hipocótilo. Silva et al. (2009) também verificaram que a correlação entre arquitetura e produtividade de grãos foi negativa e de pequena magnitude, ao avaliar progênies de plantas de porte ereto e prostradas. Na safra de 2009, a produtividade de grãos correlacionou-se com a nota de arquitetura na colheita. As demais características primárias também tiveram efeito na determinação da arquitetura de plantas de feijão.
Tabela 4. Estimativas dos efeitos diretos e indiretos das variáveis primárias sobre a variável principal nota de arquitetura (diagramas 1 e 3), no inverno de 2007 e $2009^{(1)}$.

\begin{tabular}{|c|c|c|}
\hline Efeito & 2007 & 2009 \\
\hline Efeito direto sobre NAC & \multicolumn{2}{|c|}{ Produtividade } \\
\hline Efeito indireto via AR & $-0,0743$ & 0,0042 \\
\hline Efeito indireto via NVHP & $-0,0094$ & 0,0432 \\
\hline Efeito indireto via NGV/M100 & 0,0439 & 0,0023 \\
\hline Efeito indireto via VR & $-0,0026$ & 0,1074 \\
\hline Efeito indireto via DH & 0,5130 & 0,0652 \\
\hline Efeito indireto via NRT & 0,0138 & $-0,0103$ \\
\hline Efeito indireto via CE1 & 0,1686 & 0,0148 \\
\hline \multirow[t]{2}{*}{ Total } & 0,1372 & 0,0400 \\
\hline & \multicolumn{2}{|c|}{ Angulo de insercão dos ramos } \\
\hline Efeito direto sobre NAC & 0,3670 & 0,3123 \\
\hline Efeito indireto via $\mathrm{AR}$ & 0,1045 & $-0,0025$ \\
\hline Efeito indireto via NVHP & $-0,2464$ & $-0,0881$ \\
\hline Efeito indireto via NGV/M100 & $-0,0075$ & 0,0173 \\
\hline Efeito indireto via VR & $-0,0008$ & 0,1577 \\
\hline Efeito indireto via DH & 0,6342 & 0,5125 \\
\hline Efeito indireto via NRT & 0,0010 & $-0,0076$ \\
\hline Efeito indireto via CE1 & 0,0223 & $-0,0185$ \\
\hline \multirow[t]{2}{*}{ Total } & 0,8741 & 0,8832 \\
\hline & \multicolumn{2}{|c|}{ Número de vagens na haste principal } \\
\hline Efeito direto sobre NAC & 0,4583 & 0,1167 \\
\hline Efeito indireto via $\mathrm{AR}$ & 0,0106 & $-0,0690$ \\
\hline Efeito indireto via NVHP & $-0,1973$ & $-0,2358$ \\
\hline Efeito indireto via NGV/M100 & 0,0309 & $-0,0136$ \\
\hline Efeito indireto via VR & 0,0011 & $-0,1032$ \\
\hline Efeito indireto via $\mathrm{DH}$ & $-0,4275$ & $-0,4528$ \\
\hline Efeito indireto via NRT & $-0,0031$ & 0,0083 \\
\hline Efeito indireto via CE1 & $-0,2508$ & 0,0309 \\
\hline Total & $-0,3777$ & $-0,7183$ \\
\hline \multirow{9}{*}{$\begin{array}{l}\text { Efeito direto sobre NAC } \\
\text { Efeito indireto via AR } \\
\text { Efeito indireto via NVHP } \\
\text { Efeito indireto via NGV/I } \\
\text { Efeito indireto via VR } \\
\text { Efeito indireto via DH } \\
\text { Efeito indireto via NRT } \\
\text { Efeito indireto via CE1 } \\
\text { Total }\end{array}$} & \multicolumn{2}{|c|}{ NGV/MIO0 } \\
\hline & $\begin{array}{r}0,1250 \\
-0,1811\end{array}$ & $\begin{array}{r}0,0403 \\
-0,0106\end{array}$ \\
\hline & $-0,0222$ & 0,1342 \\
\hline & 0,1135 & $-0,0395$ \\
\hline & 0,0016 & 0,0621 \\
\hline & 0,0893 & 0,1426 \\
\hline & 0,0117 & $-0,0044$ \\
\hline & 0,0751 & $-0,0075$ \\
\hline & 0,2129 & 0,3172 \\
\hline & Núme & amos \\
\hline Efeito direto sobre NAC & $-0,0250$ & 0,2343 \\
\hline Efeito indireto via AR & $-0,0534$ & $-0,0855$ \\
\hline Efeito indireto via NVHP & 0,0120 & 0,2103 \\
\hline Efeito indireto via NGV/M100 & $-0,0201$ & $-0,0514$ \\
\hline Efeito indireto via VR & $-0,0078$ & 0,0107 \\
\hline Efeito indireto via $\mathrm{DH}$ & 0,2207 & 0,2638 \\
\hline Efeito indireto via NRT & 0,0316 & $-0,0184$ \\
\hline Efeito indireto via CE1 & 0,0336 & $-0,0039$ \\
\hline Total & 0,1917 & 0,5598 \\
\hline & $\mathrm{Di}$ & \\
\hline Efeito direto sobre NAC & $-0,8879$ & $-0,7475$ \\
\hline Efeito indireto via $A R$ & 0,2980 & 0,0163 \\
\hline Efeito indireto via NVHP & $-0,2621$ & $-0,2141$ \\
\hline Efeito indireto via NGV/M100 & 0,2206 & 0,0707 \\
\hline Efeito indireto via VR & $-0,0126$ & $-0,0077$ \\
\hline Efeito indireto via DH & 0,0062 & $-0,0827$ \\
\hline Efeito indireto via NRT & $-0,0047$ & 0,0022 \\
\hline Efeito indireto via CE1 & $-0,1693$ & 0,0413 \\
\hline Total & $-0,8117$ & $-0,9216$ \\
\hline & & \\
\hline Efeito direto sobre NAC & 0,0392 & $-0,0272$ \\
\hline Efeito indireto via $\mathrm{AR}$ & $-0,1820$ & $-0,0705$ \\
\hline Efeito indireto via NVHP & 0,0092 & 0,0867 \\
\hline Efeito indireto via NGV/M100 & $-0,0357$ & $-0,0358$ \\
\hline Efeito indireto via VR & 0,0372 & 0,0066 \\
\hline Efeito indireto via DH & $-0,0202$ & 0,1580 \\
\hline Efeito indireto via NRT & 0,1066 & 0,0607 \\
\hline Efeito indireto via CE1 & 0,0299 & $-0,0059$ \\
\hline Total & $-0,0159$ & 0,1726 \\
\hline & Com & trenó \\
\hline Efeito direto sobre NAC & 0,4496 & $-0,0891$ \\
\hline Efeito indireto via $\mathrm{AR}$ & $-0,1934$ & 0,0309 \\
\hline Efeito indireto via NVHP & 0,0182 & 0,0648 \\
\hline Efeito indireto via NGV/M100 & $-0,2557$ & $-0,0405$ \\
\hline Efeito indireto via VR & 0,0209 & 0,0034 \\
\hline Efeito indireto via DH & $-0,0019$ & 0,0102 \\
\hline Efeito indireto via NRT & 0,3344 & 0,3463 \\
\hline Efeito indireto via CE1 & 0,0026 & $-0,0018$ \\
\hline Total & 0,3747 & 0,3241 \\
\hline $\mathrm{R}^{2}$ & 0,9873 & 0,9838 \\
\hline Efeito residual & 0,1129 & 0,1271 \\
\hline
\end{tabular}

(1)NAC, nota de arquitetura na colheita; AR, ângulo de inserção dos ramos; NVHP, número de vagens na haste principal; NGV/M100, número de grãos por vagem (2007) e massa de 100 grãos (2009); VR, número de vagens nos ramos; DH, diâmetro do hipocótilo; NRT, número de ramos totais; e CE1, comprimento do primeiro entrenó. 
Constatou-se que os efeitos diretos e indiretos secundários das variáveis secundárias sobre a principal (nota de arquitetura na colheita), quantificados via variáveis explicativas primárias (Tabelas 5 e 6), foram majoritariamente de pequena magnitude, tanto em 2007 quanto em 2009. Nesses dois anos, sobressaiuse a característica secundária altura média de plantas na colheita, com valores de $-0,76$, para efeito direto secundário, e de $-0,83$, para correlação com nota de arquitetura (Tabela 5, diagrama 1), em 2007, e de $-0,99$ e $-0,95$ (Tabela 6 , diagrama 3) em 2009. O maior efeito dessa variável em nota de arquitetura na colheita também foi via diâmetro do hipocótilo, para os dois anos de avaliação. De modo semelhante, Acquaah et al. (1991) apontaram o diâmetro do hipocótilo e a altura da planta como os principais indicadores efetivos da arquitetura de planta no feijoeiro.

Ao se considerar as safras isoladamente, a característica secundária dias até a colheita teve destaque em 2007, com valores de correlação de $-0,69$ e efeito direto secundário de $-0,75$ (Tabela 5 , diagrama 2). Já em 2009 (Tabela 6, diagrama 4), destacaram-se as características altura de inserção da primeira vagem, com efeito direto secundário sobre

Tabela 5. Efeitos diretos e indiretos secundários das variáveis secundárias sobre a variável principal, nota de arquitetura, via variáveis primárias (diagramas 1 e 2), para o inverno de $2007^{(1)}$.

\begin{tabular}{|c|c|c|c|c|c|c|c|c|c|c|}
\hline Efeito & EST & PROD & $\mathrm{AR}$ & NVHP & NGV & NVR & $\mathrm{DH}$ & NTR & CE1 & ER \\
\hline Diagrama 1 & \multicolumn{10}{|c|}{ Dias até o florescimento } \\
\hline Direto sobre NAC & $-0,1338$ & 0,0183 & 0,0254 & 0,2330 & $-0,0144$ & $-0,0010$ & $-0,2692$ & 0,0032 & $-0,3777$ & 0,2486 \\
\hline Indireto via $\mathrm{A} 1 \mathrm{~V}$ & $-0,0203$ & 0,0806 & 0,0181 & $-0,0615$ & $-0,0037$ & 0,0009 & 0,0558 & $-0,0022$ & 0,0339 & $-0,1421$ \\
\hline Indireto via altura na colheita & $-0,3785$ & $-0,0029$ & $-0,1507$ & 0,0807 & 0,0103 & 0,0003 & $-0,2759$ & 0,0000 & 0,0258 & $-0,0660$ \\
\hline Indireto via NERV & 0,0046 & $-0,0216$ & $-0,0080$ & $-0,0019$ & 0,0008 & $-0,0019$ & 0,0044 & 0,0029 & 0,0072 & 0,0226 \\
\hline \multirow[t]{2}{*}{ Total } & $-0,5279$ & 0,0744 & $-0,1152$ & 0,2503 & $-0,0071$ & $-0,0017$ & $-0,4848$ & 0,0039 & $-0,3109$ & 0,0632 \\
\hline & \multicolumn{10}{|c|}{ Altura de inserção da primeira vagem } \\
\hline Direto sobre NAC & $-0,0905$ & 0,3599 & 0,0807 & $-0,2746$ & $-0,0165$ & 0,0040 & 0,2493 & $-0,0099$ & 0,1512 & $-0,6346$ \\
\hline Indireto via dias até o florescimento & $-0,0300$ & 0,0041 & 0,0057 & 0,0522 & $-0,0032$ & $-0,0002$ & $-0,0603$ & 0,0007 & $-0,0846$ & 0,0557 \\
\hline Indireto via altura na colheita & 0,0434 & 0,0003 & 0,0173 & $-0,0092$ & $-0,0012$ & 0,0000 & 0,0316 & 0,0000 & $-0,0030$ & 0,0076 \\
\hline Indireto via NERV & 0,0217 & $-0,1023$ & $-0,0378$ & $-0,0091$ & 0,0036 & $-0,0088$ & 0,0210 & 0,0139 & 0,0340 & 0,1071 \\
\hline \multirow[t]{2}{*}{ Total } & $-0,0553$ & 0,2621 & 0,0659 & $-0,2407$ & $-0,0173$ & $-0,0051$ & 0,2417 & 0,0048 & 0,0976 & $-0,4643$ \\
\hline & \multicolumn{10}{|c|}{ Nota de arquitetura das plantas } \\
\hline Direto sobre NAC & $-0,7572$ & $-0,0058$ & $-0,3015$ & 0,1614 & 0,0206 & 0,0006 & $-0,5520$ & 0,0000 & 0,0516 & $-0,1320$ \\
\hline Indireto via dias até o florescimento & $-0,0669$ & 0,0092 & 0,0127 & 0,1165 & $-0,0072$ & $-0,0005$ & $-0,1345$ & 0,0016 & $-0,1888$ & 0,1243 \\
\hline Indireto via $\mathrm{A} 1 \mathrm{~V}$ & 0,0052 & $-0,0206$ & $-0,0046$ & 0,0157 & 0,0009 & $-0,0002$ & $-0,0143$ & 0,0006 & $-0,0087$ & 0,0364 \\
\hline Indireto via NERV & $-0,0062$ & 0,0291 & 0,0107 & 0,0026 & $-0,0010$ & 0,0025 & $-0,0060$ & $-0,0040$ & $-0,0097$ & $-0,0305$ \\
\hline \multirow[t]{2}{*}{ Total } & $-0,8251$ & 0,0118 & $-0,2827$ & 0,2962 & 0,0133 & 0,0024 & $-0,7068$ & $-0,0018$ & $-0,1555$ & $-0,0019$ \\
\hline & \multicolumn{10}{|c|}{ Número de entrenós nos ramos com vagem } \\
\hline Direto sobre NAC & 0,0608 & $-0,2860$ & $-0,1056$ & $-0,0254$ & 0,0101 & $-0,0246$ & 0,0588 & 0,0390 & 0,0950 & 0,2995 \\
\hline Indireto via dias até o florescimento & $-0,0101$ & 0,0014 & 0,0019 & 0,0176 & $-0,0011$ & $-0,0001$ & $-0,0204$ & 0,0002 & $-0,0286$ & 0,0188 \\
\hline Indireto via A1V & $-0,0323$ & 0,1287 & 0,0289 & $-0,0982$ & $-0,0059$ & 0,0014 & 0,0891 & $-0,0035$ & 0,0541 & $-0,2269$ \\
\hline Indireto via altura na colheita & 0,0770 & 0,0006 & 0,0307 & $-0,0164$ & $-0,0021$ & $-0,0001$ & 0,0561 & 0,0000 & $-0,0052$ & 0,0134 \\
\hline Total & 0,0954 & $-0,1554$ & $-0,0442$ & $-0,1223$ & 0,0010 & $-0,0233$ & 0,1837 & 0,0357 & 0,1153 & 0,1049 \\
\hline Diagrama 2 & \multicolumn{10}{|c|}{ Dias até a colheita } \\
\hline Direto sobre NAC & $-0,7467$ & 0,0885 & $-0,2916$ & 0,1706 & $-0,0151$ & 0,0114 & $-0,6751$ & $-0,0191$ & $-0,0805$ & 0,0642 \\
\hline Indireto via NEHP & 0,0541 & $-0,0032$ & 0,0199 & 0,1191 & $-0,0003$ & $-0,0032$ & $-0,0293$ & 0,0048 & $-0,0735$ & 0,0198 \\
\hline \multirow[t]{2}{*}{ Total } & $-0,6926$ & 0,0853 & $-0,2716$ & 0,2897 & $-0,0154$ & 0,0082 & $-0,7044$ & $-0,0143$ & $-0,1540$ & 0,0839 \\
\hline & \multicolumn{10}{|c|}{ Número de entrenós na haste principal } \\
\hline Direto sobre NAC & 0,1375 & $-0,0082$ & 0,0506 & 0,3025 & $-0,0006$ & $-0,0081$ & $-0,0744$ & 0,0121 & $-0,1866$ & 0,0502 \\
\hline Indireto via dias até a colheita & $-0,2941$ & 0,0349 & $-0,1148$ & 0,0672 & $-0,0060$ & 0,0045 & $-0,2659$ & $-0,0075$ & $-0,0317$ & 0,0253 \\
\hline Total & $-0,1566$ & 0,0266 & $-0,0642$ & 0,3696 & $-0,0066$ & $-0,0036$ & $-0,3403$ & 0,0046 & $-0,2183$ & 0,0754 \\
\hline
\end{tabular}

${ }^{(1)} \mathrm{EST}$, estimativa; PROD, produtividade de grãos; AR, ângulo de inserção dos ramos; NVHP, número de vagens na haste principal; NGV, número de grãos por vagem; NVR, número de vagens nos ramos; DH, diâmetro do hipocótilo; NTR, número total de ramos; CE1, comprimento do primeiro entrenó, ER, efeito residual; NAC, nota de arquitetura na colheita; A1V, altura de inserção 1ํㅡ vagem; NERV, número de entrenós nos ramos com vagens; NEHP, número de entrenós na haste principal. 
Tabela 6. Estimativas dos efeitos diretos e indiretos secundários das variáveis secundárias sobre a variável principal, nota de arquitetura, via variáveis primárias (diagramas 3 e 4), para o inverno de $2009^{(1)}$.

\begin{tabular}{|c|c|c|c|c|c|c|c|c|c|c|}
\hline Efeito & EST & PROD & A1V & NVHP & M100 & NVR & DH & NTR & CE1 & ER \\
\hline Diagrama 3 & \multicolumn{10}{|c|}{ Altura na colheita } \\
\hline Direto sobre NAC & $-0,9921$ & $-0,0771$ & $-0,2205$ & 0,0132 & $-0,0175$ & $-0,0429$ & $-0,5315$ & $-0,0069$ & $-0,0385$ & $-0,0704$ \\
\hline Indireto via grãos por vagem & 0,0030 & 0,0032 & 0,0034 & 0,0003 & 0,0013 & 0,0032 & 0,0016 & $-0,0001$ & $-0,0012$ & $-0,0087$ \\
\hline Indireto via NEHP & $-0,0933$ & $-0,0043$ & $-0,0197$ & 0,0311 & $-0,0044$ & $-0,0102$ & $-0,1463$ & $-0,0027$ & 0,0443 & 0,0189 \\
\hline Indireto via NERV & 0,1362 & 0,0716 & $-0,0052$ & 0,0224 & 0,0044 & $-0,1032$ & 0,1463 & 0,0130 & $-0,0012$ & $-0,0120$ \\
\hline \multirow[t]{2}{*}{ Total } & $-0,9463$ & $-0,0066$ & $-0,2421$ & 0,0670 & $-0,0161$ & $-0,1531$ & $-0,5300$ & 0,0034 & 0,0034 & $-0,0721$ \\
\hline & \multicolumn{10}{|c|}{ Número de grãos por vagem } \\
\hline Direto sobre NAC & $-0,0505$ & $-0,0546$ & $-0,0574$ & $-0,0046$ & $-0,0228$ & $-0,0540$ & $-0,0265$ & 0,0018 & 0,0198 & 0,1479 \\
\hline Indireto via altura na colheita & 0,0582 & 0,0045 & 0,0129 & $-0,0008$ & 0,0010 & 0,0025 & 0,0312 & 0,0004 & 0,0023 & 0,0041 \\
\hline Indireto via NEHP & 0,0529 & 0,0024 & 0,0112 & $-0,0177$ & 0,0025 & 0,0058 & 0,0830 & 0,0015 & $-0,0251$ & $-0,0107$ \\
\hline Indireto via NERV & 0,0858 & 0,0451 & $-0,0033$ & 0,0141 & 0,0028 & $-0,0650$ & 0,0921 & 0,0082 & $-0,0007$ & $-0,0075$ \\
\hline \multirow[t]{2}{*}{ Total } & 0,1464 & $-0,0025$ & $-0,0366$ & $-0,0090$ & $-0,0166$ & $-0,1106$ & 0,1798 & 0,0119 & $-0,0038$ & 0,1338 \\
\hline & \multicolumn{10}{|c|}{ Número de entrenós na haste principal } \\
\hline Direto sobre NAC & $-0,1621$ & $-0,0074$ & $-0,0343$ & 0,0541 & $-0,0076$ & $-0,0178$ & $-0,2542$ & $-0,0046$ & 0,0769 & 0,0328 \\
\hline Indireto via altura na colheita & $-0,5711$ & $-0,0444$ & $-0,1269$ & 0,0076 & $-0,0101$ & $-0,0247$ & $-0,3059$ & $-0,0040$ & $-0,0222$ & $-0,0405$ \\
\hline Indireto via grãos por vagem & 0,0165 & 0,0178 & 0,0187 & 0,0015 & 0,0075 & 0,0176 & 0,0087 & $-0,0006$ & $-0,0065$ & $-0,0483$ \\
\hline Indireto via NERV & 0,0453 & 0,0238 & $-0,0017$ & 0,0074 & 0,0015 & $-0,0343$ & 0,0486 & 0,0043 & $-0,0004$ & $-0,0040$ \\
\hline \multirow[t]{2}{*}{ Total } & $-0,6714$ & $-0,0102$ & $-0,1442$ & 0,0706 & $-0,0087$ & $-0,0592$ & $-0,5029$ & $-0,0049$ & 0,0479 & $-0,0600$ \\
\hline & \multicolumn{10}{|c|}{ Número de entrenós nos ramos com vagem } \\
\hline Direto sobre NAC & $-0,2194$ & $-0,1154$ & 0,0084 & $-0,0361$ & $-0,0071$ & 0,1663 & $-0,2357$ & $-0,0210$ & 0,0019 & 0,0193 \\
\hline Indireto via altura na colheita & 0,6157 & 0,0479 & 0,1368 & $-0,0082$ & 0,0109 & 0,0266 & 0,3298 & 0,0043 & 0,0239 & 0,0437 \\
\hline Indireto via grãos por vagem & 0,0197 & 0,0213 & 0,0225 & 0,0018 & 0,0089 & 0,0211 & 0,0104 & $-0,0007$ & $-0,0077$ & $-0,0578$ \\
\hline Indireto via NEHP & 0,0334 & 0,0015 & 0,0071 & $-0,0112$ & 0,0016 & 0,0037 & 0,0524 & 0,0010 & $-0,0159$ & $-0,0068$ \\
\hline Total & 0,4495 & $-0,0447$ & 0,1748 & $-0,0536$ & 0,0143 & 0,2176 & 0,1570 & $-0,0165$ & 0,0022 & $-0,0016$ \\
\hline Diagrama 4 & \multicolumn{10}{|c|}{ Dias até o florescimento } \\
\hline Direto sobre NAC & $-0,3632$ & 0,0168 & $-0,0541$ & 0,0257 & $-0,0050$ & 0,0576 & $-0,5251$ & $-0,0097$ & 0,0530 & 0,0776 \\
\hline Indireto via $\mathrm{A} 1 \mathrm{~V}$ & $-0,1519$ & 0,0013 & $-0,0394$ & 0,0078 & $-0,0030$ & $-0,0336$ & $-0,0656$ & 0,0015 & $-0,0049$ & $-0,0160$ \\
\hline \multirow[t]{2}{*}{ Total } & $-0,5151$ & 0,0180 & $-0,0935$ & 0,0335 & $-0,0080$ & 0,0240 & $-0,5907$ & $-0,0082$ & 0,0481 & 0,0616 \\
\hline & \multicolumn{10}{|c|}{ Altura de inserção da $1 \stackrel{\text { a }}{ }$ vagem } \\
\hline Direto sobre NAC & $-0,7453$ & 0,0062 & $-0,1934$ & 0,0383 & $-0,0148$ & $-0,1649$ & $-0,3219$ & 0,0075 & $-0,0239$ & $-0,0783$ \\
\hline Indireto via dias até o florescimento & $-0,0740$ & 0,0034 & $-0,0110$ & 0,0052 & $-0,0010$ & 0,0117 & $-0,1070$ & $-0,0020$ & 0,0108 & 0,0158 \\
\hline Total & $-0,8193$ & 0,0096 & $-0,2044$ & 0,0436 & $-0,0158$ & $-0,1532$ & $-0,4289$ & 0,0055 & $-0,0131$ & $-0,0625$ \\
\hline
\end{tabular}

(1)EST, estimativa; PROD, produtividade de grãos; A1V, altura de inserção 1ํㅡ vagem; NVHP, número de vagens na haste principal; M100, massa de 100 gãos; NVR, número de vagens nos ramos; DH, diâmetro do hipocótilo; NTR, número total de ramos; CE1, comprimento do primeiro entrenó; ER, efeito residual; NAC, nota de arquitetura na colheita; NEHP, número de entrenós na haste principal; e, NERV, número de entrenós nos ramos com vagens.

nota de arquitetura de $-0,75$ e correlação de $-0,82$, e dias até o florescimento, com efeito direto secundário de $-0,36$ e correlação de $-0,52$. Novamente, os maiores efeitos dessas variáveis sobre a nota de arquitetura na colheita foram via diâmetro do hipocótilo.

O segundo atributo dos caracteres a serem utilizados na seleção indireta de plantas mais eretas é o elevado efeito direto relacionado à elevada correlação genotípica com a nota de arquitetura. Assim, o diâmetro do hipocótilo pode ser utilizado como caráter auxiliar na seleção indireta de plantas mais eretas. É importante notar que a mensuração dessa característica, além de ser fácil e ágil, não é subjetiva, como a atribuição de notas.

\section{Conclusões}

1. Os caracteres diâmetro do hipocótilo, ângulo de inserção dos ramos e altura de plantas na colheita são os principais determinantes da arquitetura de plantas do feijoeiro.

2. O diâmetro do hipocótilo é indicador efetivo da arquitetura de plantas do feijoeiro e pode subsidiar, ou até mesmo substituir, a avaliação por notas. 


\section{Referências}

ACQUAAH, G.; ADAMS, M.W.; KELLY, J.D. Identification of effective indicators of erect plant architecture in dry bean. Crop Science, v.31, p.261-264, 1991. DOI: 10.2135/cropsci1991.00111 83X003100020004x.

BASSETT, M.J. List of genes - Phaseolus vulgaris L. Annual Report of the Bean Improvement Cooperative, v.47 p.1-24, 2004.

COLliCCHIO, E.; RAMALHO, M.A.P.; ABREU, A. de F.B. Associação entre o porte da planta do feijoeiro e o tamanho dos grãos. Pesquisa Agropecuária Brasileira, v.32, p.297-304, 1997.

CRUZ, C.D. Programa Genes: biometria. Viçosa: Ed. UFV, 2006. 382p.

CRUZ, C.D.; CARNEIRO, P.C.S. Modelos biométricos aplicados ao melhoramento genético. 2.ed. Viçosa: Ed. UFV, 2006. v.2, $585 \mathrm{p}$.

CRUZ, C.D.; REGAZZI, A.J.; CARNEIRO, P.C.S. Modelos biométricos aplicados ao melhoramento genético. 3.ed. Viçosa: Ed. UFV, 2004. v.1, 480p.

CUNHA, W.G. da; RAMALHO, M.A.P.; ABREU, Â. de F.B. Selection aiming at upright growth habit common bean with carioca type grains. Crop Breeding and Applied Biotechnology, v.5, p.379-386, 2005.

FALCONER, D.S.; MACKAY, T.F.C. Introduction to quantitative genetics. $4^{\text {th }}$ ed. London: Longman, 1996. 463p.

MENDES, F.F.; RAMALHO, M.A.P.; ABREU, A. de F.B. Índice de seleção para escolha de populações segregantes de feijoeiro-comum. Pesquisa Agropecuária Brasileira, v.44, p.1312-1318, 2009. DOI: 10.1590/ S0100-204X2009001000015.

MENEZES JÚNIOR, J.A.N. de; RAMALHO, M.A.P.; ABREU, Â. de F.B. Seleção recorrente para três caracteres do feijoeiro. Bragantia, v.67, p.833-838, 2008. DOI: 10.1590/ S0006-87052008000400004.

MORETO, A.L.; RAMALHO, M.A.P.; NUNES, J.A.R.; ABREU, A. de F.B. Estimação dos componentes da variância fenotípica em feijoeiro utilizando o método genealógico. Ciência e Agrotecnologia, v.31, p.1035-1042, 2007. DOI: 10.1590/S141370542007000400014 .

OLIVEIRA, G.V.; CARNEIRO, P.C.S.; CARNEIRO, J.E. de S.; CRUZ, C.D. Adaptabilidade e estabilidade de linhagens de feijão comum em Minas Gerais. Pesquisa Agropecuária Brasileira, v.41, p.257-265, 2006. DOI: 10.1590/S0100-204X2006000200010.

PEREIRA, H.S.; MELO, L.C.; FARIA, L.C. de; PELOSO, M.J. del; COSTA, J.G.C. da; RAVA, C.A.; WENDLAND, A. Adaptabilidade e estabilidade de genótipos de feijoeiro-comum com grãos tipo carioca na Região Central do Brasil. Pesquisa Agropecuária Brasileira, v.44, p.29-37, 2009. DOI: 10.1590/ S0100-204X2009000100005.

RAMALHO, M.A.P.; FERREIRA, D.F.; OLIVEIRA, A.C. de. Experimentação em genética e melhoramento de plantas. 2.ed. Lavras: UFLA, 2005. 322p.

RAMALHO, M.A.P.; PIROLA, L.H.; ABREU, A. de F.B. Alternativas na seleção de plantas de feijoeiro com porte ereto e grão tipo carioca. Pesquisa Agropecuária Brasileira, v.33, p.1989-1994, 1998.

SANTOS, J.B.; VENCOVSKY, R. Controle genético de alguns componentes do porte da planta em feijoeiro. Pesquisa Agropecuária Brasileira, v.21, p.957-963, 1986a.

SANTOS, J.B.; VENCOVSKY, R. Correlação fenotípica e genética entre alguns caracteres agronômicos do feijoeiro (Phaseolus vulgaris L.). Ciência e Prática, v.10, p.265-272, 1986 b.

SILVA, C.A.; ABREU, A. de F.B.; RAMALHO, M.A. Associação entre arquitetura de planta e produtividade de grãos em progênies de feijoeiro de porte ereto e prostrado. Pesquisa Agropecuária Brasileira, v.44, p.1647-1652, 2009. DOI: 10.1590/ S0100-204X2009001200013.

SILVA, V.M.P. Melhoramento genético do porte do feijoeiro. 2011. 60p. Tese (Doutorado) - Universidade Federal de Viçosa, Viçosa.

TEIXEIRA, F.F.; RAMALHO, M.A.P.; ABREU, A.F.B. Genetic control of plant architecture in the common bean (Phaseolus vulgaris L.). Genetics and Molecular Biology, v.22, p.577-582, 1999. DOI: 10.1590/S1415-47571999000400019. 